\title{
IDENTIDADE E MEMÓRIA: RESSIGNIFICANDO CAMINHOS
}

\section{IDENTITY AND MEMORY: RESIGNING PATHS}

\author{
Lúcia Matias da Silva ${ }^{10}$ \\ Márcia Maria Martinelli Elias ${ }^{11}$
}

\section{RESUMO}

$\mathrm{O}$ artigo traz a narrativa da experiência profissional transformada após a trajetória da pós-graduação, momento em que os sentidos da docência ganham novos contornos. Para chegar a esse recorte, recorre-se à narração da escolha da profisssão e dos primeiros passos na carreira, bem como dos desafios surgidos e que culminaram na necessidade de buscar novas perspectivas profissionais. Descrever tal experiência é um exercício de rememorar espaços de construção, desconstrução e reconstrução da identidade profissional para reavivar reflexões e explorar aprendizagens. Nesse percurso, ocorrem rupturas ao questionar um habitus que parece não mais responder aos questionamentos imputados pelo cotidiano e que requerem novas disposições que, gradativamente, agregam-se a um modus operandi renovador. A construção do conhecimento atrelada a uma prática reflexiva é capaz de mudar o discurso, o olhar, a interpretação e a leitura de mundo produzida pela teoria compreensiva do cotidiano. A reflexão da abordagem experiencial toma as histórias de vida como prática de formação e têm significado transformar o olhar sobre a própria docência e dar-lhe contornos mais expressivos, uma vez que permite confrontar diferentes singularidades presentes na prática profissional. Como a interpretação, o sentido e o discurso docente podem promover mudanças, à guisa de conclusão, a Professora Márcia Maria Martinelli Elias, nos brinda, com uma perspectiva possível, considerações sobre o olhar acerca do papel dos sentidos na interpretação de contextos como componente de transformação da realidade.

Palavras-chave: Experiência profissional. Docência. Aprendizagem. Mudança.

\section{INTRODUÇÃO}

Narrar experiências, descrever sentidos encontrados a partir do exercício de rememorar a trajetória percorrida é um espaço para reavivar reflexões e explorar os sentidos de suas vivências e aprendizagens. Os estudos, que se apropriam da abordagem experiencial e que tomam as histórias de vida como prática de formação, têm

\footnotetext{
${ }^{10}$ Mestre e Doutora em Educação. Atua profissionalmente na Escola de Aplicação da Faculdade de Educação da Universidade de São Paulo - EAFEUSP. Faculdades Integradas Potencial - FIP Cotia. Licenciatura em Geografia e Pedagogia. Especialista em Gestão Escolar.

${ }^{11}$ Doutora e Mestre em Linguística em Língua Portuguesa. Atua profissionalmente na Faculdades Integradas Potencial - FIP - Cotia. Licenciatura em Letras e Pedagogia
} 
significado transformar o olhar sobre a própria docência e dar-lhe contornos mais expressivos, uma vez que permite confrontar diferentes singularidades presentes na prática profissional.

Conforme Souza, Sousa e Catani (2007), o movimento biográfico no Brasil tem sua vinculação com as pesquisas na área educacional, seja no âmbito da História da Educação, da Didática e Formação de Professores, bem como em outras áreas que tomam as narrativas como perspectiva de pesquisa e de formação.

Revisitar trajetórias é algo que não se fixa apenas no campo subjetivo, já que toda vivência, ainda que singular, situa-se também num contexto histórico e cultural. A memória é uma experiência histórica indissociável das experiências peculiares de cada indivíduo e de cada cultura. Segundo Bosi (2003), existe um substrato social da memória articulada com a cultura, tomada em toda sua diversidade estética, política, econômica e social.

Como pensar a partir do reconhecimento da importância da subjetividade na formação docente? De que forma ela pode contribuir para uma profissionalidade docente mais lúcida e transformadora? Os estudos das histórias de vida no campo educacional centram-se na pessoa do professor, com ênfase nas subjetividades e identidades que as histórias comportam.

O narrar de si envolve a temática de ordem vivencial. Narrando de si o sujeito tem por temática sua própria vida, aquilo que marca a sua existência e a singulariza. Pensar o sujeito e sua heterogeneidade constitutiva implica, ainda, o olhar do outro, a compreensão, o acolhimento e todas as nuances de uma relação consigo mesmo, com a profissão, de modo que seja, em última instância, um espaço de partilha.

\section{BREVE BIBLIOGRAFIA}

Não somos aquilo que fizeram de nós, mas o que fazemos com o que fizemos de nós (Jean Paul Sartre)

Minha trajetória profissional carrega, desde seus primórdios, uma profunda admiração pelo ofício de ensinar, aliada à lembrança de professores significativos que ao longo de minha experiência deixaram marcas que sempre representaram estímulo decisivo para que eu persistisse na busca da excelência do trabalho docente. Os elogios, os gestos e atitudes de muitos professores funcionam como molas propulsoras capazes 
de transformar vontade em ações que, a partir das relações interpessoais nos processos de ensinar e aprender se traduziram em caminhos que ultrapassaram as barreiras das condições objetivas.

Optei pelo magistério na década de 1980 e entre todas as atribuições inerentes ao curso se inclui também a própria docência como substituta, ministrava aulas de maneira recorrente e estava em pleno processo de greve de professores do Governo Maluf que, no entanto, não eram muito discutidas nem por mim, nem pelos professores que lecionavam para o curso.

Depois de formada, atuei como professora das séries iniciais do ensino fundamental no Instituto São Pio X em Osasco, um período importante para o entendimento da estrutura organizacional de uma escola, além da própria organização do trabalho pedagógico. Nesse período, ingressei na Faculdade para o curso de Estudos Sociais e ainda, atuava no período da manhã com aulas em substituição na rede estadual de ensino.

A partir de 1986, ingressei na rede estadual como professora de Geografia, após conclusão da complementação em Geografia exigida para aqueles que haviam cursado Estudos Sociais. Em 1988, decidi fazer o curso de Pedagogia, pois, além de julgar que essa formação me ajudaria como professora, também ambicionava trabalhar na coordenação e na gestão das escolas públicas estaduais.

Concomitante à rede estadual em 1994, assumi aulas no SESI e em escolas particulares de pequeno porte, porém decidi ficar apenas na rede estadual em 1998, quando fui convidada a atuar como vice-diretora de escola, função que permaneci até 2006. Nesse período, senti uma insatisfação com relação às funções desempenhadas na escola, uma impotência diante de desafios que pareciam não ter solução, uma solidão, uma tristeza que foi, aos poucos, me tirando o prazer que sempre tive em estar na escola, foi um período em que a satisfação de ser professora parecia ameaçada.

Diante disso resolvi fazer alguma coisa, mudar de ares e me inscrevi para atuar como tutora no Projeto Pec - Formação Universitária pela Universidade de São Paulo. Felizmente fui chamada e, obviamente, que esse trabalho representava um desafio para quem estava imerso na escola pública e distante dos bancos escolares já há tanto tempo.

Na primeira edição do projeto, em 2001, trabalhei no Polo de Carapicuíba; conheci muita gente e me vi diante de um material impresso relevante para responder a muitas questões, não só dos alunos envolvidos no programa, mas também, afinal eu 
também era oriunda da escola pública.

O aprendizado da tecnologia para interação com a Universidade foi extremamente importante num momento em que as escolas começaram a receber computadores administrativos e pedagógicos. Tudo era feito por e-mail e nossa comunicação com a Universidade era feita por meio dessa ferramenta, além disso, no Polo, os alunos tinham atividades do Learnig Space e necessitavam de apoio constante, as videoconferências eram semanais, a teleconferência mensal e o envolvimento com toda essa dinâmica de trabalho me fez enxergar uma luz no fim do túnel, recuperar a autoestima, ganhar ânimo novo e a partir daí resolvi investir na minha formação.

A orientadora de TCC da minha turma era a professora Flavinês Lapo que à época era doutoranda da Profa. Dra. Belmira Bueno da Faculdade de Educação da USP e me incentivou a ir para a pós-graduação. No entanto, em função de problemas particulares tive que adiar esse projeto e ainda trabalhei no PEC na segunda edição no período noturno entre 2003 e 2004.

Em 2005, fiz um curso na USP de "Introdução aos estudos da educação" com a Profa. Dra. Maria Nazaré de Camargo Pacheco Amaral, como aluna especial da rede pública, pois buscava suporte para ingressar na pós-graduação. Em 2006, ingressei na UNICAMP para um curso de especialização em Gestão Educacional oferecido pela rede estadual de ensino do estado de São Paulo para gestores em exercício. Tínhamos aulas presenciais aos sábados e atividades em EaD durante a semana. Para mim, foi uma experiência muito significativa, pois, além de aprender a lidar com as ferramentas do $\mathrm{EaD}$ na condição de aluna, o repertório do curso agregou conhecimentos importantes à minha formação.

Nesse mesmo ano, prestei o processo seletivo para o mestrado na PUCSP e fui aprovada no programa de Estudos Pós-Graduados em Educação: História, Política, Sociedade. Em 2007, comecei o mestrado, ao mesmo tempo em que assumi a direção da escola estadual onde trabalhava desde 1986. Foi um período intenso e a participação nas aulas, aos poucos, foi me inocentando de tantas culpas pela impotência que sentia diante dos problemas vividos na escola e para os quais não encontrava solução.

Assumi uma pesquisa no Programa de Estudos Pós-graduados em Educação: História, Política, Sociedade, na linha de pesquisa Educação e Ciências Sociais sob a orientação da Profa. Dra. Luciana Maria Giovanni. Resolvi investigar a relação professor aluno e ampliar minha percepção acerca dos traços culturais presentes nessa 
relação tão conflituosa na minha realidade profissional. Tal fato se mostrava antagônico em face da minha experiência tão significativa como aluna e também como professora, pois sempre tive boa relação com meus professores e alunos.

Os resultados da pesquisa contribuíram para meu entendimento acerca dos motivos de tal conflito vivido na escola, e se não me trouxe soluções em curto prazo, ao menos, me ajudou a compreender a ocorrência de tal fenômeno (SILVA, 2009). Em 2010, com o incentivo de minha orientadora do mestrado Profa. Dra. Luciana Maria Giovanni e da Profa. Dra. Alda Junqueira Marin ingressei no doutorado da PUCSP para pesquisar a dimensionalidade da profissão docente por meio da análise da identidade de professores em exercício. Os resultados de tal investigação me trouxeram a certeza, provisória é verdade, do quanto a atuação de professores e do processo de escolarização podem ser decisivas na vida pessoal e profissional do sujeito social (SILVA, 2014). São marcas que a experiência põe à prova cotidianamente.

A complexidade dessa experiência reside, por um lado, justamente no caráter sempre inacabado das disposições, já que o sujeito age sobre o que lhe acontece (LAHIRE, 2004), porém esse movimento não pode ser entendido de maneira dissociada da ordem de razões, da qual ele tira o sentido de suas ações, e dos contextos de inserção, consciência e vontade individuais (BOURDIEU, 2003). Essa dinâmica revela uma relação em parte indeterminada entre o modo como o profissional se vê e o modo como é visto, por sua inserção em um meio social, fato que constitui e reconstitui sua identidade profissional (DUBAR, 2005).

Já de posse dessa metamorfose gradativa, em 2013, passei a atuar como professora no curso de Pedagogia da Universidade Nove de Julho nas modalidades presencial e a distância, experiência rica de uma vivência que, aos poucos, norteou os caminhos que quero percorrer como professora e pesquisadora. Em 2014, saiu minha aposentadoria na rede estadual de ensino e passei a atuar apenas na Universidade. Em 2015, trabalhei num curso de pós-graduação na FMU como professora convidada para a disciplina de mediação pedagógica e, no segundo semestre, ministrei duas disciplinas da pós-graduação em Docência para o ensino superior na Faculdade Sumaré. Para essa mesma turma, fui convidada a orientar o TCC com o projeto "Identidade e Memória". Desse trabalho resultam 13 artigos sobre a temática que envolve o processo de recuperar as memórias escolares para melhor compreender a prática pedagógica, publicado em revista eletrônica da instituição. 
Após desenvolver esse trabalho, recebi o convite para atuar como professora da graduação em Pedagogia da Faculdade Sumaré, ao mesmo tempo em que estabeleço conversas sobre a escrita de projeto para o pós-doutoramento na Universidade de São Paulo com a Profa. Dra. Paula Perin Vicentini, com vistas a aprofundar discussões sobre a temática da identidade e memória como recurso para uma autorreflexão e dimensionamento das práticas no exercício profissional.

O projeto do pós-doutoramento acaba adiado em função de compromissos profissionais que subtraem o tempo necessário para sua realização, sempre nos lembrando do quanto as condições objetivas têm peso decisivo nas escolhas que fazemos.

Em 2018, desenvolvi trabalho no curso de pós-graduação lato sensu da Universidade Salesiana - Unisal - campus Lorena, com o módulo de avaliação. Discutir o tema com profissionais de diferentes áreas de atuação se mostrou uma contribuição importante e relevante para o entendimento de diferentes perspectivas da docência. Atualmente, trabalho na Escola de Aplicação da Universidade de São Paulo EAFEUSP - uma experiência desafiadora ao impelir, todos os dias, o exercício da articulação teoria e prática no desenvolvimento de conteúdos e projetos interdisciplinares. Atuo também nas Faculdades Integradas Potencial - FIP Campus Cotia - com as disciplinas pedagógicas nos cursos de Licenciatura: Letras e Pedagogia. Nesse espaço de atuação, encontrei rico espaço de discussões e troca de experiências que geraram uma postura de encorajamento para a promoção de mudanças significativas e necessárias no que se refere à formação de professores.

Passo agora a um breve relato sobre minha experiência na pós-graduação e como essa trajetória contribuiu para que pudesse olhar para minha prática e para o trabalho realizado na escola com lentes mais compreensivas e tolerantes.

\section{A EXPERIÊNCIA DA PÓS-GRADUAÇÃO}

Em 2007, comecei o mestrado da PUCSP, ao mesmo tempo em que assumi a direção da escola estadual onde trabalhava desde 1986. Penso que no momento em que vejo minha admiração pela profissão docente agonizar diante dos desafios vividos na escola, quando passei a ter clareza de que continuar atuando no espaço escolar sem encontrar caminhos possíveis e menos ainda, sem esperança de solução para que 
voltasse a sentir aquele prazer, aquela alegria de estar na escola, enchi-me de coragem para ingressar na pós-graduação e buscar as respostas que pareciam escapar à minha compreensão.

Cheguei ao extremo dessa desesperança quanto percebi que sentia vergonha de assumir meu lugar na docência, criticava minha atuação e ao mesmo tempo não encontrava resposta para transformar essa sensação que desestimula pessoal e profissionalmente. Essas representações da escola e da atuação profissional foram, sem dúvida, potencializadas no momento em que assumi a gestão da escola. Quando os impasses, desafios e conflitos chegavam diante de mim, por muitas vezes, sentia a impotência, a frustação e a tristeza por não possuir respostas possíveis, ao mesmo tempo em que desejava propor intervenções, contribuir, compreender.

Quando nosso espaço de trabalho é a sala de aula, ainda temos uma autonomia relativa para tentar escapar de algumas armadilhas que nos arrastam para o fracasso, mas quando assumimos a gestão temos a sensação de que não há mais alunos diretamente ligados à nossa prática e escolhas profissionais, no entanto, gradativamente vai se construindo uma percepção de que todos são nossos alunos, de que todos os professores precisam de nós, de que os funcionários dependem de uma clareza no norteamento de ações, de que os pais e a comunidade esperam de nós decisões pertinentes que superem ou minimizem os desafios que surgem incessantemente na rotina das escolas.

Aliada a toda essa problemática, o gestor escolar ainda necessita gerenciar toda a parte administrativa da escola, uma tarefa que é, também, bastante complexa na realidade da escola e da qual não se pode descuidar sob pena de comprometer recursos, proventos e processos que se apresentam todos os dias como urgências que não podem ser ignoradas.

A partir desse cenário, uma professora de escola pública que iniciou a carreira docente aos 18 anos e que sempre vibrou muito dentro do ambiente escolar, de tal forma que o papel social de aluna e professor parecem se fundir num continuo que sempre representou prazer e realização pessoal e profissional, adoece diante da impotência para encontrar saídas que recuperem esse imaginário.

Diante desse panorama, fui buscar o remédio na pós-graduação e minha trajetória nesse período representou um divisor de águas para que me reencontrasse com a docência, para que fizesse as pazes com minha prática, para que encontrasse 
argumentos teóricos e metodológicos que fossem capazes de construir novos sentidos à minha trajetória profissional.

No início do processo, foi perceptível as lacunas de formação de que eu precisava superar, mas abracei esse desafio com muito empenho, pois a cada dia sentia o descortinamento de outra perspectiva para interpretar o trabalho na escola. Fui, paulatinamente, construindo disposições traduzidas em lentes mais tolerantes para enxergar a rotina da escola, derrubando julgamentos, retomando a autoestima, recuperando sentidos para o exercício profissional.

Essas disposições construídas pelo sujeito possuem relação com o mundo, o indivíduo não se produz isolado da sociedade, ele é uma realidade social caracterizada por sua complexidade disposicional, que se manifesta na diversidade dos domínios de práticas ou cenários nos quais insere suas ações (LAHIRE, 2004).

Assim, na pesquisa sobre a relação professor-aluno no espaço de sala de aula à luz dos intervenientes presentes na cultura que permeia essa interação, foi possível inocentar professores, alunos e gestores, por meio da compreensão de que existe todo um ethos cultural que envolve essas relações práticas, além de um sistema pautado em políticas educacionais que pressionam posições contraditórias dentro de um processo complexo e antagônico.

Em 2010, ingressei no doutorado para pesquisar a dimensionalidade da profissão docente por meio da análise da identidade de professores em exercício, para tanto, a escolha metodológica pauta-se na construção e análise de retratos sociológicos desses profissionais. Os resultados de tal investigação me trouxe a certeza, provisória é verdade, do quanto a atuação de professores e do processo de escolarização podem ser decisivas na vida pessoal e profissional do sujeito social, ao considerar as disposições construídas no processo de socialização e que, gradativamente configuram um habitus que, consciente ou inconscientemente, norteia nossas ações.

Ao concluir essa longa trajetória de desconstrução, o que leva a deixar cair por terra muitas crenças pautadas no senso comum, pude reconstruir outra perspectiva da profissão docente e reavaliar minhas posições profissionais. Algumas questões que antes julgava insolúveis passo a compreender que, na verdade, são resultado de mecanismos políticos que realimentam uma estrutura escolar calcada em objetivos macroestruturais e, portanto, nenhuma contribuição trazem para a construção de uma escola democrática. Esse entendimento me fez ver que o que acontece na cultura que se 
perpetua na escola não é destino, mas contingência, ou seja, há toda uma lógica para que as coisas não mudem. Tal fenômeno é conveniente para que se mantenha uma ideologia estatal que anuncia processos democráticos e participativos sem, no entanto, prever condições efetivas para sua concretização.

Outra questão macro envolvida tem a ver, por um lado, com a formação inicial de professores e, por outro, com o modo como o capital cultural trazido pelos alunos é considerado pela escola. A formação inicial de professores parece não dar conta dos desafios enfrentados na realidade da atuação profissional e sobre isso, há aspectos ligados ao modo como as instituições promovem essa formação, bem como em relação às orientações legais sob as quais as instituições formadoras também estão subordinadas.

É importante ainda considerar que, o público que busca os cursos de formação de professores enfrentam desafios de diferentes ordens - qualidade da educação básica, parcos recursos financeiros, tempo disponível para dedicação ao curso etc. - para chegar ao final da trajetória formativa, e isso acaba por trazer consequências significativas no exercício da profissão, fatores que, sem dúvida, também representam desafios para as instituições formadoras.

Esses desafios oriundos das condições objetivas da formação inicial implicam diretamente a prática profissional desses professores que, como aponto acima, tomam de maneira distorcida o capital cultural trazido pelos alunos ao não considerar o contexto de inserção desse público, as experiências vividas como parte das metodologias de ensino, o que leva, por fim, ao desenvolvimento de um trabalho voltado à práticas homogeneizadoras que, em nada contribuem ao atendimento diversificado que deveria ocorrer em nossas escolas.

Pior que chegar a essa conclusão é ter a clara percepção de que, grande parte dos professores em exercício nas nossas escolas, não têm clareza desses entraves e julgam que na prática, o trabalho realizado é satisfatório e os alunos não correspondem ao esperado pelo universo escolar. A culpabilização, na maioria das vezes, recai sobre o aluno e este, por sua vez, não tem quem o defenda, o que os leva a acreditar que a escola e seus mecanismos excludentes é boa e eles é que são fracassados por terem diante de si uma escola que não considera suas necessidades e expectativas.

$\mathrm{Na}$ prática, isso significa mudar apenas nome e data nos planejamentos anuais, não refletir teoricamente sobre o trabalho desempenhado em sala de aula, não planejar 
as aulas, afinal o tempo reduzido impede tais ações, negativas em relação à participação nos colegiados, à construção do Projeto Político Pedagógico, entre outros.

Pude perceber, após minha experiência na pós-graduação que, na verdade, professores e alunos vivem, na maioria de nossas escolas, experiências que não permitem avançar rumo à formação almejada. $\mathrm{O}$ discurso de uma escola democrática que busca formar alunos que exerçam uma cidadania plena e efetiva não se coaduna à realidade que encontramos nas escolas e que são relatadas não apenas pela minha experiência no período em que atuei como gestora de escola pública, mas também nos resultados de pesquisas divulgados todos os dias pelos pesquisadores em educação.

São dados que expõem uma realidade perversa; no entanto, quando se vive a experiência de professor-pesquisador é possível tomar ciência de tais mecanismos e, assim, reinterpretar as demandas e desafios que a educação básica enfrenta hoje.

Atuar hoje no ensino superior no curso de Pedagogia, a par de todos esses mecanismos excludentes e perversos que estão presentes nas entrelinhas das políticas educacionais vigentes em nosso país, faz com que eu busque construir um discurso que contemple essas questões e tenha um posicionamento mais tolerante frente aos desafios enfrentados pelos alunos e alunas e um olhar que busca compreender toda a problemática que envolve não só a profissão docente, mas também os desafios da formação em função dos públicos presentes nos cursos de formação de professores.

Esse deciframento de ações, ultrapassa as intenções objetivas, os projetos conscientes, individuais e coletivos; vai além ao relacionar diretamente práticas e propriedades inscritas na situação contextual, sem esquecer que as relações interpessoais são relações de indivíduo a indivíduo só aparentemente, pois eles transportam com eles, em todo tempo e lugar, a posição presente e passada na estrutura social, então não é indivíduo e indivíduo que se relacionam, mas habitus, disposições, pessoas sociais (BOURDIEU, 2003).

Parece pertinente dizer que hoje, a partir da contribuição de estudos na pósgraduação, vejo toda a realidade diante de meus olhos como contingência de processos políticos e econômicos excludentes e por isso mesmo, faço outra leitura acerca das demandas colocadas para a formação de professores. Entender que nossas dificuldades não são irreversíveis, mas que podem ser transformadas a partir de processos formativos que permitam exercício profissional mais equânime alimenta e realimenta minha prática, mesmo sabendo que podemos estar diante da utopia anunciada, não posso me 
furtar a encarar esse desafio. Hoje reinterpreto toda dinâmica envolvida no campo educacional à luz de estudos teóricos que, ao contrário do que muitos acreditam, muito elucidam o entendimento da prática.

É possível dizer, portanto, que a construção do conhecimento, atrelada a uma prática reflexiva, é capaz de mudar o discurso, o olhar, a interpretação e a leitura de mundo produzida por professores em exercício. Parece, ainda, urgente reiterar como esse processo transforma o sujeito não apenas no âmbito profissional, mas também promove amadurecimento pessoal e dá à quem o realiza condições de compreender o cenário, a sociedade e a própria vida em movimento.

Como a interpretação, o sentido e o discurso docente podem promover mudanças, à guisa de conclusão, a Professora Márcia Maria Martinelli Elias, nos brinda, de uma perspectiva possível, considerações sobre o olhar acerca do papel dos sentidos na interpretação de contextos como componente de transformação da realidade.

\section{PRÁTICAS DOCENTES RESSIGNIFICADAS}

Quando o professor vai à busca de novos conhecimentos científicos, ele lança, sobre sua prática pedagógica, um olhar crítico e torna-se capaz de interpretá-la, avaliá-la e, se necessário, recriá-la. De modo que novos saberes ampliam não só a atuação pedagógica do professor, como também sua relação com os alunos e sua percepção do cenário social e político que estão, intrinsecamente, ligados à educação.

As relações dialógicas - fenômeno bem mais amplo do que as relações entre as réplicas do diálogo expresso composicionalmente - são um fenômeno quase universal, que penetra toda a linguagem humana e todas as relações e as manifestações da vida humana, em suma, tudo que tem sentido e importância (BAKHTIN, 1992, p 42).

Ter o domínio do conhecimento científico, muda a visão e o repertório do docente. Seu discurso se converte em outro; as dificuldades, inerentes à prática docente, passam a ser entendidas como situações que podem ser transformadas, uma vez que o professor concebe a escola sem o véu da perfeição, mas com os olhos voltados à realidade.

O saber científico é o que legitima a prática docente, o professor, ao se sentir compelido a ampliar suas habilidades profissionais, desenvolve, também, sua vida 
pessoal o que gera mudanças significativas em seu modo de pensar e de agir na docência.

Nessa perspectiva, a procura por novos conhecimentos implica mudanças na prática, no discurso e na organização didática das aulas, visto que a pós-graduação leva o professor a apreender novos conceitos, se apropriar deles e transformá-los em ações pedagógicas voltadas ao aluno, à escola e à comunidade.

Torna-se evidente que o professor, ao optar pela educação continuada, reflete sobre sua prática docente, identifica as lacunas a serem preenchidas com as novas teorias, constata as dificuldades que irá encontrar ao implementar mudanças; porém é capaz de enfrentar os desafios exigidos, pois vislumbra como será seu ponto de partida, seu percurso e seu permanente caráter provisório. Por isso, Bakhtin afirma que "a compreensão responsiva do conjunto discursivo é sempre de índole dialógica" (BAKHTIN, 1992, p. 332).

A pesquisa conduz o professor a ampliar não somente o saber dentro da sua área de atuação, vai além, uma vez que ela amplifica seu modo de conceber o mundo e, assim, o docente apropria-se das necessidades ligadas à docência e gestão escolar.

Essa busca por novos saberes é consequência da necessidade de apossar-se de novas possibilidades, como de incluir na prática docente novas metodologias. Enfim, quando o professor se angustia em seu fazer docente e se sente desmotivado frente aos desafios, muitos encontram suporte na pesquisa e passam, a partir daí, a compreender a realidade escolar, para depois superar paradigmas, ressignificando, assim, esse fazer, por meio de atitudes mais assertivas à sua prática.

Tal processo representa um trabalho de desconstrução, uma vez que as convicções do professor são substituídas por novas perspectivas e a prática docente, nesse momento, passa a ser construída sob um novo viés, porque ainda que a situação esteja estagnada dentro do ambiente escolar, o professor revestiu-se de um novo repertório. Ele deixa de lado a sua maneira de pensar e constrói novas disposições, de forma mais consciente e próxima da sua realidade sem deixar, no entanto, de imprimir à prática o rigor do conhecimento acadêmico.

Um professor, ao se tornar pesquisador, agrega à sua prática docente um modus operandi diverso, reveste-se de um novo discurso, uma vez que adquiriu, por meio dos novos conhecimentos, uma outra forma de pensar e enxergar a realidade na educação, assim, a maneira com que lida com as contingências não são as mesmas. Ele se apossou 
do saber e, assim, é capaz de interpretar os desafios e vislumbrar outros caminhos possíveis. Está aberto às mudanças e à superação de paradigmas, com foco no desenvolvimento do aluno e no próprio desenvolvimento científico.

Ressalta-se que o docente, ao apropriar-se de uma nova visão das suas necessidades, pressupõe que estas são reversíveis, pois é capaz de transmutá-las. Assim, quando o professor enxerga a educação à luz dos conhecimentos científicos, exerce sua função plena de educador, deixa de ser um executor de tarefas, faz leituras mais assertivas do cotidiano e forja ações voltadas para a articulação entre teoria e prática, de modo que fatos e fenômenos sejam abordados à luz dessa concepção fulcral para a educação.

\section{REFERÊNCIAS}

BAKHTIN, M. Os gêneros do discurso (1952-1953). In: Estética da criação verbal. São Paulo: Martins Fontes, p. 277-326, 1992.

BOURDIEU, P. A sociologia de Pierre Bourdieu. São Paulo: Olho D’água, 2003.

BOSI, E. O tempo vivo da memória. São Paulo: Ateliê Editorial, 2003.

CUNHA, M. I. Conta-me agora! As narrativas como alternativas pedagógicas na pesquisa e no ensino. Rev. Fac. Educ. vol. 23, n.1-2, São Paulo, Jan./Dec. 1997.

DUBAR, C. A socialização: construção das identidades sociais e profissionais. São Paulo: Marins Fontes, 2005.

LAHIRE, B. Retratos Sociológicos: Disposições e Variações Individuais. Porto Alegre: Artmed, 2004.

SARTRE, J. P. O ser e o nada. Disponível em:

https://meuartigo.brasilescola.uol.com.br/filosofia/o-existencialismo-sartre.htm.

SILVA, L. M. da. A relação professor-aluno: traços culturais presentes na interação em sala de aula. Dissertação de Mestrado. Pontifícia Universidade Católica de São Paulo: PUCSP, 2009.

SILVA, L. M. da. As formas identitárias nos contextos de trabalho: Uma análise da profissionalidade docente. Tese de doutorado. Pontifícia Universidade Católica de São Paulo: PUCSP, 2014.

SOUZA, E. C. de; SOUSA, C. de; CATANI, D. B. La reserche (auto) biographique et l'invention de soi au Bresil. Colloque International (1986- 2007) Le Biographique, la réflexivité et les temporalités. Articuler Langues, cultures et formation. Université FrançoisRabelais, 25-27 juin 2007, Tours-França. 